\title{
Benign Soft Palate Neoplasm
}

National Cancer Institute

\section{Source}

National Cancer Institute. Benign Soft Palate Neoplasm. NCI Thesaurus. Code C4404.

A non-metastasizing neoplasm that arises from the soft palate or uvula. 